\title{
Efficacy and safety of proprotein convertase subtilisin-kexin type 9 (PCSK9) inhibitors, alirocumab and evolocumab, a post-commercialization study
}

\author{
Joshua Choi, Amir M Khan*, Michael Jarmin, Naila Goldenberg, Charles J Glueck and Ping Wang
}

\begin{abstract}
Background: Efficacy-safety of proprotein convertase subtilisin-kexin type 9 (PCSK9) inhibitors, alirocumab (ALI) and evolocumab (EVO), have previously been evaluated through controlled clinical trials with selective patient groups. Post-commercially, in 69 patients with heterozygous familial hypercholesterolemia (HeFH) and/or cardiovascular disease (CVD) with suboptimal LDL cholesterol (LDLC) lowering on maximal tolerated LDLC therapy, we assessed efficacy and safety of ALI and EVO.
\end{abstract}

Methods: Post-commercially, we started 29 patients on ALI 75 mg, 18 on ALI 150 mg, and 22 on EVO 140 mg every 2 weeks added to a maximally tolerated LDLC-lowering regimen. Since LDLC lowering did not differ between ALI 150 and EVO 140 mg, ALI 150-EVO 140 data were pooled (ALI-EVO). Changes in LDLC and AHA and NIH calculated 10-year CVD risks were assessed.

Results: Of the 69 patients, 25 had HeFH, 25 CVD, and 19 had both. At entry, 23 (33\%) took statins and 46 (67\%) were statin-intolerant. Mean \pm SD and median follow-up were $49 \pm 13$ and 49 weeks on ALI 75 mg, and $37 \pm 12$ and 33 weeks on ALI-EVO. In the ALI-EVO group $(n=40)$, median LDLC fell from $165 \mathrm{mg} / \mathrm{dl}$ at entry to $70 \mathrm{mg} / \mathrm{dl}$ (median - 59\%, $p<.0001$ ). AHA 10-year calculated CVD risk fell from 10.2 to $5.5 \%$ (median - 28\%, $p<.0001$ ), and by the $\mathrm{NIH}$ calculator from 14.2 to $3.6 \%$ (median - 78\%, $p<.0001$ ). In the ALI $75 \mathrm{mg}$ group $(n=29)$, entry LDLC fell from 115 to $68 \mathrm{mg} / \mathrm{dl}$ (median - 39\%, $p$ <.0001). AHA 10-year calculated CVD risk fell from 11.5 to $7.3 \%$ (median - 20\%, $p=.004$ ), and $\mathrm{NIH} 10$-year risk from 12.9 to $5.1 \%$ (median $67 \%, p<.0001$ ). Absolute and percent change in LDLC was independent of statin use. There were flu-like symptoms in $14 \%$ of patients. Adverse events did not differ $(p>0.05)$ between ALI $75 \mathrm{mg}$ and ALI-EVO.

Conclusion: In patients with HeFH and/or CVD, LDLC decreased from 115 to 68 mg/dl (39\%) on ALI 75 mg with mean follow-up of 49 weeks, and from 165 to $70 \mathrm{mg} / \mathrm{dl}$ (59\%) on ALI-EVO over 37 weeks, $p<.0001$ for both. Adverse events were minimal and tolerable. ALI and EVO represent paradigm shifts in LDLC lowering.

Keywords: PCSK9 inhibitor, Efficacy, Safety, Cardiovascular risk, Alirocumab, Evolocumab, Hypercholesterolemia, Low-density lipoprotein

\footnotetext{
* Correspondence: AKhan@mercy.com

Graduate Medical Education and Research, The Jewish Hospital- Mercy

Health, Graduate Medical Education and Research, Cincinnati, USA
} 


\section{Background}

Before commercialization, efficacy and safety of alirocumab (ALI) and evolocumab (EVO) in patients has been evaluated through randomized controlled clinical trials [1-5] with stringent inclusion and exclusion criteria, creating highly selective cohorts of study patients. ALI and EVO have approved indications in patients with heterozygous familial hypercholesterolemia (HeFH), Simon Broom's Criteria, [6] and/or WHO Dutch Lipid Criteria, [7] and/or in patients with cardiovascular disease (CVD) with suboptimal LDLC lowering despite maximal tolerated cholesterol lowering therapy. Previously, we have projected that an estimated 24 million Americans could be eligible for PCSK9 inhibitor therapy $[8,9]$.

ALI ODYSSEY Phase III studies demonstrated that the mean percentage change in calculated low-density lipoprotein cholesterol (LDLC) from baseline to week 24 beyond statin effect was $-61 \%$ versus $0.8 \%$ (placebo), $p<0.001$. $[2,10]$ The Odyssey Combo 1 phase 3 study enrolled 316 patients with CHD or CHD risk equivalents and hypercholesterolemia, providing ALI $75 \mathrm{mg}$ every 2 weeks (Q2W) which was increased to $150 \mathrm{mg}$ Q2W if week $8 \mathrm{LDLC}$ was $\geq 70 \mathrm{mg} / \mathrm{dl}$ [11]. All patients also took maximally tolerated statin therapy. At week 24 mean LDL had fallen $46 \%$ beyond placebo, $p<.0001$. LDLC $<70$ was achieved by $75 \%$ on ALI vs $9 \%$ placebo at week 24. Treatment Emergent Adverse Events (TEAE) were comparable between groups.

The Odyssey Combo II trial [12] was a 104 week study of ALI $75 \mathrm{mg}$ Q2W vs ezetimibe in patients with high cardiovascular risk and elevated LDLC despite maximal doses of statin. At week 24, mean reductions in LDLC were $50.6 \%$ for ALI vs $20.7 \%$ for ezetimibe, and $45.6 \%$ of patients achieved LDLC $<70 \mathrm{mg} / \mathrm{dl}$. There was no excess of TEAE when compared to ezetimibe.

In Odyssey Choice II, ALI $150 \mathrm{mg}$ Q4W or $75 \mathrm{mg}$ Q2W were used with dose adjustment to 150 Q2W at week 12 if pre-defined LDLC levels were not met [13]. Overall, $63.9 \%$ and $70.3 \%$ of ALI treated patients achieved their LDLC goals at week 24. Patients with inadequately controlled hypercholesterolemia and not on a statin were included.

In pooled analyses of 6 trials of ALI including 4211 patients for 52 weeks or longer, there was no evidence for transition to new-onset diabetes in 3448 cases without diabetes at entry with a follow up period of 6-18 months, compared to either placebo or ezetimibe [14]. The safety of ALI has been evaluated in pooled data from 14 trials, double blind treatment for 8 to 104 weeks, in 3340 ALI and 1894 controls (placebo or ezetimibe) with focus on patients with at least 2 consecutive LDLC levels $<25$ or once $<15 \mathrm{mg} / \mathrm{dl}$ [15]. There was no increase in overall TEAE event rates or neurocognitive events, although cataract incidence appeared to be increased in the group achieving LDLC $<25 \mathrm{mg} / \mathrm{dl}$.

Sabatine et al. have reported that EVO reduced the level of LDLC by $61 \%$ from a median of 120 to $48 \mathrm{mg} / \mathrm{dl}$. The rate of cardiovascular events at 1 year was reduced from $2.18 \%$ in the standard therapy group to $0.95 \%$ in the EVO group, hazard ratio $0.47,95 \%$ CI $0.2-0.78, p=.003$ [4]. In the LAPLACE- 2 randomized trial, Robinson et al. reported that EVO reduced LDLC by 66 to $75 \%$ and by 63 to $75 \%$ vs placebo at the mean of weeks 10 and 12 , respectively, in the moderate and high intensity statintreated groups [16]. Nissen has reported efficacy and tolerance in patients with statin intolerance [1] with a 54\% lowering of LDLC on EVO. Koren et al. [17] have recently summarized data from 4641 patient-years among 1255 patients randomized to EVO in one of five placebocontrolled phase II studies (GAUSS-1, RUTHERFORD-1, YUKAWA-1, MENDEL-1, or LAPLACE-TIMI 57), and followed-up for an average of 44 months. The median LDLC reduction over baseline was $57 \%$, similar to the $61 \%$ seen at 12 months in the original studies. Safety was maintained in the open-label follow-up.

While OSLER-1 follow-up showed a median LDL of $60 \mathrm{mg} / \mathrm{dL}$ on long-term EVO, the second study - a prespecified analysis of the intensive lipid-lowering IMPROVE-IT trial - looked at the safety of levels below $30 \mathrm{mg} / \mathrm{dL}$. Giugliano et al. [18] have recently reported “...patients achieving an LDL-C level less than $30 \mathrm{mg} / \mathrm{dL}$ at 1 month had a similar safety profile (and numerically the lowest rate of cardiovascular events) over a 6-year period compared with patients achieving higher LDL-C concentrations."

In the Fourier trial, 27,564 patients with ASCVD and LDLC $\geq 70 \mathrm{mg} / \mathrm{dl}$ who were receiving statin therapy took EVO $140 \mathrm{mg}$ Q2W or $420 \mathrm{mg}$ every month with matching placebo, with median duration of follow-up 2.2 years [19]. The primary efficacy end point was the composite of cardiovascular death, myocardial infarction, stroke, hospitalization for unstable angina, or coronary revascularization. The key secondary efficacy end point was the composite of CVD death, MI, or stroke. At 48 weeks, LDLC on EVO was reduced 59\% from 92 to $30 \mathrm{mg} / \mathrm{dl}$. Relative to placebo, EVO reduced the risk of the primary endpoint $9.8 \%$ vs $11.3 \%$, hazard ratio $0.85,95 \%$ CI 0.79 to $0.92, p<.001$ and the key secondary endpoint from $5.9 \%$ vs $7.4 \%$, hazard ratio $0.80,95 \% \mathrm{CI}$ 0.73 to $0.89, p<.001$. There were no case-control differences in adverse events, excepting injection site reactions, $2.1 \%$ with EVO vs $1.6 \%$ control $[17,19]$.

In the GLAGOV randomized trial [20] in 846 patients with evaluable imaging (IVUS) at follow-up, compared to placebo the EVO group had lower mean LDLC, 37 vs $93 \mathrm{mg} / \mathrm{dl}$. EVO induced plaque regression in a greater percentage of patients than placebo, $64.3 \%$ vs $47.3 \%$, difference $17 \%, 95 \%$ CI $10.4 \%$ to $23.6 \%, p=.001$. After 
76 weeks of treatment, EVO compared to placebo, resulted in a greater decrease in PAV.

We previously carried out an open label efficacy and safety 24-week study of ALI and EVO in 72 patients with $\mathrm{HeFH}$ and/or CVD with suboptimal LDL cholesterol (LDLC) lowering on maximal tolerated cholesterol lowering therapy [21]. Post-commercially, we started 25 patients on ALI $75 \mathrm{mg}, 15$ on ALI $150 \mathrm{mg}$, and 32 on EVO 140 mg every 2 weeks added to a maximally tolerated entry LDLC lowering regimen, with follow-up for a median 24 weeks. At 24 weeks, on ALI 75 mg, median LDLC decreased from 117 to $62 \mathrm{mg} / \mathrm{dL}(-54 \%)$, on ALI $150 \mathrm{mg}$, LDLC fell from 175 to $57 \mathrm{mg} / \mathrm{dL}(-63 \%)$, and on EVO $140 \mathrm{mg}$, LDLC fell from 165 to $69 \mathrm{mg} / \mathrm{dL}$ (-63\%), $p<0.0001$ for all. Absolute and percent LDLC reduction did not differ $(p>.05)$ between ALI 150 and EVO $140 \mathrm{mg}$, but were less on ALI $75 \mathrm{mg}$ vs ALI $150 \mathrm{mg}$ and EVO $140 \mathrm{mg}(p<.05)$ [21]. Percent reductions in 10-year CVD risks by AHA and NIH calculators, respectively were ALI $75 \mathrm{mg}-22 \%$ and $-44 \%$, ALI $150 \mathrm{mg}-31 \%$ and $-50 \%$, and EVO $140 \mathrm{mg}-29 \%$ and $-56 \%, p \leq .002$ for all [21]. The three most common adverse events included flu-like myositis $10 \%$, respiratory tract symptoms $8 \%$, and injection site reaction 6\% [21]. Adverse events were minimal and tolerable.

Statin intolerance, predominantly myalgia, myositis, and myopathy, occurs in 10-29\% of statin-treated patients [22, 23]. In the GAUSS-3 study of patients with previous statin intolerance, $43 \%$ of patients on atorvastatin had muscular symptoms. When ezetimibe and placebo were compared to EVO and placebo, 29\% experienced myalgias on ezetimibe versus $21 \%$ of those on EVO [1]. Furthermore, LDLC reduction from baseline on ezetimibe was $-17 \%$ versus $-53 \%$ on $\mathrm{EVO}$ at 24 weeks. In these patients with statin intolerance, EVO was effective and well-tolerated [1].

Our specific aim, in an extended [21] postcommercialization, open label study, was to assess the safety and efficacy of ALI and EVO in lowering LDLC, and subsequent change in calculated 10-year CVD risk in patients with $\mathrm{HeFH}$ and/or CVD referred to a regional cholesterol center for diagnosis and treatment of hypercholesterolemia.

\section{Methods}

The procedures were in accordance with the ethical standards of human experimentation, and approved by The Jewish Hospital Institutional Review Board.

Since the commercialization of PCSK9 inhibitors in July 2015 at our regional cholesterol center, 69 patients had extended ( $>24$ weeks) follow up on either EVO $140 \mathrm{mg}$ Q2W $(n=22)$ or ALI $150 \mathrm{mg}$ Q2W $(n=18)$ or ALI 75 Q2W $(n=29)$. They qualified for PCSK9 therapy by HeFH (Simon Broom's Criteria [6], WHO Dutch
Lipid Criteria score $>8$ [7]), and/or CVD with suboptimal LDLC lowering despite maximal tolerated cholesterol lowering therapy, including statin doses down to zero. HeFH was assessed by the presence of tendon xanthomas and LDLC $\geq 190 \mathrm{mg} / \mathrm{dl}$ and/or personal or family history of premature cardiovascular disease and/or history of severe hypercholesterolemia. CVD was defined as carotid artery disease, history of stroke/TIA, coronary artery disease, congestive heart failure associated with CVD, and peripheral vascular disease.

Prior to initiation of therapy, all patients were counseled on a low cholesterol and saturated fat diet, and received follow-up counseling at serial visits. Instructions on how to use PCSK9 inhibitor auto-injector pens, education on its mechanism of action and side effects, and steps to be taken for missed doses were provided. Emergency contact information was given.

ALI and EVO were given in addition to patients' entry maximal tolerated cholesterol lowering regimens. Insurance formulary coverage was taken into consideration when deciding whether to use ALI or EVO. ALI $75 \mathrm{mg}$ was approved by insurance formulary coverage in 29 patients, 10 with entry LDLC $\geq 130 \mathrm{mg} / \mathrm{dl}$, ALI $150 \mathrm{mg}$ was approved for 18 patients, 15 with entry LDLC $\geq 130 \mathrm{mg} / \mathrm{dl}$, and EVO $140 \mathrm{mg}$ was approved in 22 patients, 17 with entry LDLC $\geq 130 \mathrm{mg} / \mathrm{dl}$. Subcutaneous auto-injector pens were used every 2 weeks.

We previously [21] reported 24 week treatment follow-up for 23 of the 29 patients currently on ALI $75 \mathrm{mg}, 12$ of the 18 currently on ALI $150 \mathrm{mg}$, and 17 of the 22 currently on EVO $140 \mathrm{mg}$. Now we report extended follow-up for 29 patients on ALI 75 for a mean of 49 weeks, and for 40 on ALI-EVO for a mean of 37 weeks.

We recorded patient characteristics including age, gender, weight, body mass index, systolic and diastolic blood pressures, history of diabetes, smoking, and treatment with anti-hypertensive medications. Adverse events after the initiation of the therapy were recorded. Changes in 10-year cardiovascular risk were assessed using ACC/AHA [24] and NIH Framingham [25] risk calculators.

\section{Statistical methods}

Statistical software SAS version 9.4 and Prism were used for data analysis and presentation.

To determine whether the ALI $150 \mathrm{mg}$ and EVO $140 \mathrm{mg}$ Q2W data could be pooled, stepwise multiple regression was carried out with absolute or percent change (from entry to last follow up) in LDLC as the dependent variable and age, BMI, LDLC at entry, sex, race, duration of follow-up, concomitant lipid lowering therapy, $\mathrm{HeFH}, \mathrm{CVD}$ and three PCSK9 treatment groups as explanatory variables. The concomitant lipid lowering 
therapy was classified as statin alone, statin plus ezetimbe and/or colesevelam, only ezetimibe and/or colesevelam, and no lipid lowering therapy.

To determine if the LDLC lowering by ALI $75 \mathrm{mg}$ or combined ALI-EVO was influenced by concomitant statin use, general linear models were used to calculate LS means of absolute or percent change in LDLC in patients taking statins, and in the no statin group after adjusting for PCSK9 treatment and treatment duration, age, BMI and LDLC at entry, race, gender, $\mathrm{HeFH}(+/-)$, and CVD $(+/-)$.

Paired Wilcoxon tests were used to compare entry and follow-up data. Chi-square tests were used to assess the adverse effects (any vs none) between ALI 75 and combined ALI-EVO groups, and between taking statin and not taking statin groups.

\section{Results}

Table 1 displays entry characteristics of our cohort of 69 patients. Median age at entry was 64 years, $88 \%$ Caucasian, 9\% African-American, 1\% Asian, and 1\% Indian. Of the 69 patients, $52 \%$ were female, $48 \%$ male, $13 \%$ had diabetes, $4 \%$ smoked, and $62 \%$ were on anti-hypertensive medication. Of the 69 patients, 25 (36\%) had HeFH only, 25 (36\%) had CVD only, and 19 (28\%) had both HeFH and CVD (Table 1). Of the 69 patients, 46 (67\%) could not tolerate any dose of statin (Table 1). Before starting ALI or EVO, 13 patients were taking a statin only, 3 statin and ezetimibe, 1 statin and colesevelam, 6 statin, ezetimibe, and colesevelam, and 7 ezetimibe and/or colesevelam and 39 (57\%) took no lipid lowering therapy (Table 1).

By stepwise regression, there was no difference in LDLC lowering $(p>0.05)$ between ALI $150 \mathrm{mg}$ and EVO $140 \mathrm{mg}$. Hence, we pooled data from 18 patients taking ALI $150 \mathrm{mg}$ and 22 taking EVO $140 \mathrm{mg}$ Q2W (ALI-EVO).

As displayed in Table 2, on ALI $75 \mathrm{mg}$, median LDLC fell from $115 \mathrm{mg} / \mathrm{dl}$ at entry to $68 \mathrm{mg} / \mathrm{dl}$ after a mean of 49 weeks treatment, a median 39\% decrement, $p<.0001$. Ten year calculated CVD risk by the AHA calculator fell from 11.5 to $7.3 \%(p=.0008)$, a median decrement of $20 \%(p=.004)$, and by the NIH calculator fell from 12.9 to $5.1 \%(p<.0001)$, a median decrement of $67 \%, p<.0001$, Table 2 .

Table 169 patients at study entry before treatment with Alirocumab or Evolocumab

\begin{tabular}{|c|c|}
\hline $\begin{array}{l}\text { Age at entry (years) } \\
\text { Mean } \pm \text { SD, [25th, 50th, 75th percentiles] }\end{array}$ & $61.7 \pm 9.4,[55,64,69]$ \\
\hline $\begin{array}{l}\text { BMI }\left(\mathrm{kg} / \mathrm{m}^{2}\right) \\
\text { Mean } \pm \text { SD, }[25 \text { th, 50th, } 75 \text { th percentiles }]\end{array}$ & $29.5 \pm 4.8,[25.5,29.0,32.0]$ \\
\hline Race & $\begin{array}{l}61 \text { White (88\%), } 6 \text { Black (9\%), } 1 \text { Asian (1\%), } \\
1 \text { Indian (1\%) }\end{array}$ \\
\hline Gender & 36 F (52\%), 33 M (48\%) \\
\hline Diabetes & 9 Yes (13\%), 60 No (87\%) \\
\hline Smoke & 3 Yes (4\%), 66 No (96\%) \\
\hline Antihypertensive drug & 43 Yes (62\%), 26 No (38\%) \\
\hline $\mathrm{HeFH}$ & $\begin{array}{l}44 \text { Yes }(64 \%), 25 \text { No }(36 \%) ; \\
25 \text { had HeFH \& no CVD (36\%) }\end{array}$ \\
\hline CVD & $\begin{array}{l}44 \text { Yes (64\%), } 25 \mathrm{No}(36 \%) ; \\
25 \text { had CVD \& no HeFH (36\%) }\end{array}$ \\
\hline Both HeFH \& CVD & $19(28 \%)$ \\
\hline Statin intolerant & 46 Yes (67\%), 23 No (33\%) \\
\hline \multirow{4}{*}{$\begin{array}{l}\text { Medication use at entry } \\
\text { Taking Statin }(n=23)\end{array}$} & Statin only, $N=13$ \\
\hline & Statin + ezetimibe, $N=3$ \\
\hline & Statin + colesevelam, $N=1$ \\
\hline & Statin + ezetimibe + colesevelam, $N=6$ \\
\hline \multirow[t]{4}{*}{ Not taking statin $(n=46)$} & Ezetimibe only, $N=2$ \\
\hline & Colesevelam only, $N=2$ \\
\hline & Ezetimibe + colesevelam, $N=3$ \\
\hline & Nothing, $N=39$ \\
\hline Follow up weeks Mean \pm SD, [25th, 50th, 75th \%tiles] on ALI 75 mg Q2W $(n=29)$ & $49 \pm 13,[38,49,59]$ \\
\hline on ALI $150 \mathrm{mg}(n=18)$ or EVO $140 \mathrm{mg}(n=22)$ Q2W, data pooled & $37 \pm 12[26,33,45]$ \\
\hline Total cohort $(n=69)$ & $42 \pm 14[30,40,51]$ \\
\hline
\end{tabular}


Table 2 Changes in LDLC and CVD risk from study entry to last follow up visit in 69 patients taking Alirocumab 75 mg every 2 weeks $(n=29)$, or Alirocumab $150 \mathrm{mg}(n=18)$ or Evolocumab $140 \mathrm{mg}(n=22)$ every 2 weeks (ALI-EVO)

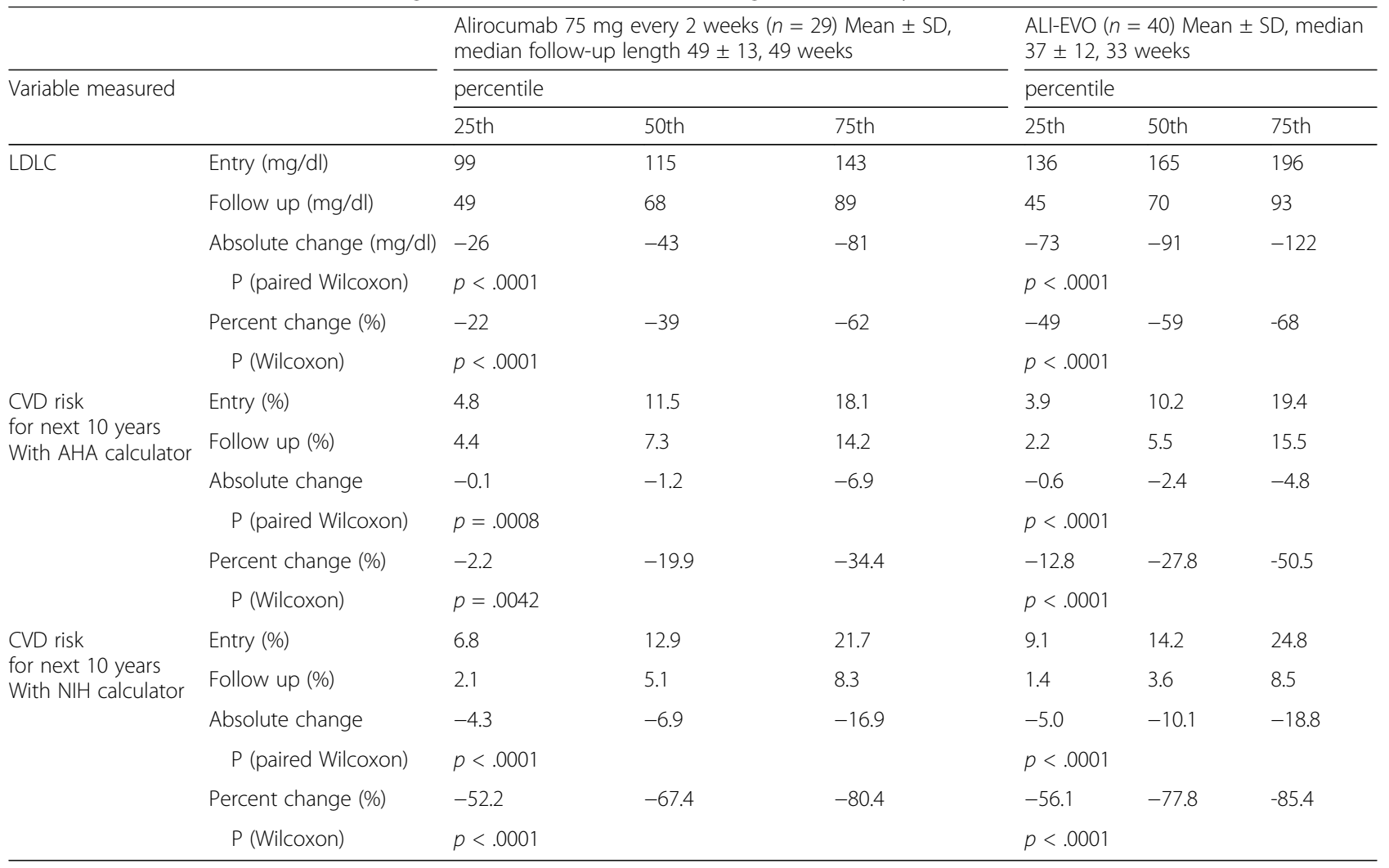

On ALI-EVO for a mean of 37 weeks, median LDLC fell from $165 \mathrm{mg} / \mathrm{dl}$ at entry to $70 \mathrm{mg} / \mathrm{dl}$, a median 59\% decrement, $p<.0001$, Table 2. On ALI-EVO, 10-year calculated CVD risk by the AHA calculator fell from 10.2 to $5.5 \%$ (median decrement $28 \%, p<.0001$ ), and by the NIH calculator from 14.2 to $3.6 \%$ (median decrement $78 \%, p<.0001)$, Table 2 .

Checking all LDLC measures during this extended follow up, in the ALI $75 \mathrm{mg}$ group, median LDLC fell from $115 \mathrm{mg} / \mathrm{dl}$ at entry to $71 \mathrm{mg} / \mathrm{dl}$ at 28 weeks $(p=.0008)$, from $122 \mathrm{mg} / \mathrm{dl}$ at entry to $68 \mathrm{mg} / \mathrm{dl}$ at 42 weeks $(p=.0002)$, and from 135 to $67 \mathrm{mg} / \mathrm{dl}$ at 52 weeks $(p<.0001)$, Fig. 1.

In the ALI-EVO group, median LDLC fell from $165 \mathrm{mg} / \mathrm{dl}$ at entry to $65 \mathrm{mg} / \mathrm{dl}$ at 28 weeks $(p<.0001)$, from $161 \mathrm{mg} / \mathrm{dl}$ at entry to $74 \mathrm{mg} / \mathrm{dl}$ at 42 weeks $(p=.0005)$, and from 149 to $78 \mathrm{mg} / \mathrm{dl}$ at 52 weeks $(p=.012)$, Fig. 2 .

On ALI $75 \mathrm{mg}$ Q2W, 15 of 29 patients (52\%) had $\geq 1$ LDLC $<70 \mathrm{mg} / \mathrm{dl}$, and $58 \%$ of their LDLC measures were $<70 \mathrm{mg} / \mathrm{dl}$, Table 3. On ALI-EVO, 20 of 40 (50\%) patients had $\geq 1 \mathrm{LDLC}<70 \mathrm{mg} / \mathrm{dl}$, and $47 \%$ of all of their LDLC determinations were $<70 \mathrm{mg} / \mathrm{dl}$, Table 3. For all 69 patients, $51 \%$ of patients had $\geq 1$ LDLC $<70 \mathrm{mg} / \mathrm{dl}$ on therapy, and $53 \%$ of all LDLC measures were $<70 \mathrm{mg} / \mathrm{dl}$, Table 3 .
On ALI $75 \mathrm{mg}$, median TG fell from 130 to 124, $p=0.06$, and median HDLC was unchanged, Table 4 . Median total cholesterol fell from 192 to 152, a median $26 \%$ reduction, $p<.0001$. Median non-HDL cholesterol fell from 136 to 50, a median 54\% reduction, $p<.0001$, Table 4.

For the ALI-EVO group, median TG fell from 161 to 119 , a median $32 \%$ reduction, $p<.0001$, and HDLC rose from 50 to $55 \mathrm{mg} / \mathrm{dl}$, a median $8 \%$ increase, $p=.0002$, Table 4. Total cholesterol fell from 255 to 154 , a $39 \%$ reduction, $p<.0001$. Median non-HDL cholesterol fell from 201 to $92 \mathrm{mg} / \mathrm{dl}$, a median 54\% reduction, $p<.0001$, Table 4 .

Neither absolute nor percentage reduction of LDLC differed between patients taking or not taking statins at entry and throughout the study, Table 5.

The most common side effect overall was flu-like symptoms in $14 \%$ of patients, followed by fatigue $(7 \%)$ in the ALI $75 \mathrm{mg}$ group and by headache or gastrointestinal symptoms ( $5 \%$ for each) in the ALI-EVO group, Table 6. No patients reported reduced cognitive function. Side effects did not differ $(p=0.11)$ between ALI 75 and ALI-EVO groups, Table 6.

When separating the cohort by entry statin intolerance, the number of adverse events experienced during ALI and EVO therapy did not differ $(p=0.11)$, Table 7 . 


\section{Change of LDLC on Alirocumab 75 mg Q2W}

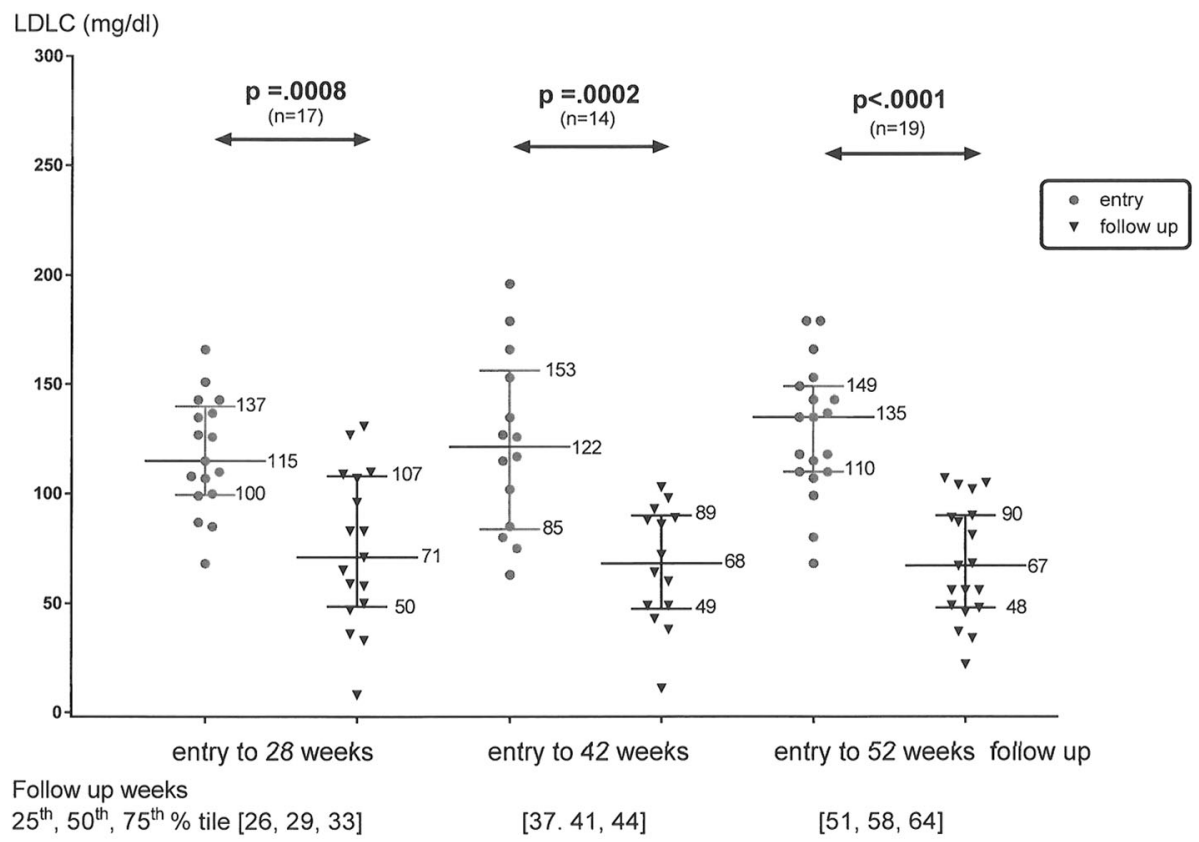

Fig. 1 Change in LDLC from entry to 28, 42, and 52 weeks on Alirocumab 75 mg every 2 weeks in 29 patients; median, 25th and 75th LDLC percentiles displayed

One patient had coronary bypass revision due to scar tissue growth within 1 month of starting ALI $150 \mathrm{mg}$ Q2W. The ALI $150 \mathrm{mg}$ was not stopped and the event was not attributed to the ALI therapy.

\section{Discussion}

Despite maximal tolerated cholesterol lowering therapy, many patients fail to achieve optimal LDLC lowering [26-28], with only $28 \%$ of patients in NHANES achieving LDLC $<70 \mathrm{mg} / \mathrm{dl}$ on treatment. [29] Failure to reach optimal LDLC lowering is predominantly related to statin intolerance [30-34]. In the current study, $67 \%$ of patients were statin intolerant, a very common, outcome limiting problem in treatment of hypercholesterolemia [22, 23, 32-35]. Of patients who discontinue statins, $60 \%$ report statin intolerance as the reason [36]. In the current study, where $67 \%$ of patients were statin intolerant at entry, reduction of LDLC by ALI or ALI-EVO did not differ between patients with or without entry statin intolerance. LDLC lowering and tolerability of EVO in the current study was congruent with evaluation of patients with statin intolerance in GAUSS-3, where EVO was well-tolerated and effective [1]. PCSK9 inhibitors now offer the promise of optimizing LDLC in the majority of patients with $\mathrm{HeFH}, \mathrm{CVD}$, and concurrent statin intolerance as previously published $[2-5,37-39]$, and as in the high risk $\mathrm{HeFH-CVD}$ patients of current report, 67\% of whom could not take any statin at any dose or sequence.

ALI and EVO have been found to be very efficacious and safe during phase II and III randomized controlled trials with minimal adverse events compared to placebo $[1,2,4,40,41]$. During phase III trials with patients on maximal tolerated cholesterol lowering therapy along with ALI $150 \mathrm{mg}$ and ALI $75 \mathrm{mg}$ Q2W, there were 61\% and $46 \%$ reductions from baseline in LDLC, respectively, at median 24 weeks $[2,11]$. In OSLER-1 and 2, patients on EVO $140 \mathrm{mg}$ Q2W or $420 \mathrm{mg}$ once/month had LDLC reduction by $61 \%$ at median 12 weeks on top of antecedent cholesterol lowering therapy [4].

Meeting both FDA indications and third party insurance drug coverage requirements, our current study was done in $\mathrm{HeFH}$ and/or CVD patients with suboptimal cholesterol lowering despite maximal tolerated cholesterol lowering therapy. This qualified all of our cohort, with minimal exclusion criteria, for initiation of ALI or EVO therapy, a cohort much more diverse than those in the placebo-controlled randomized clinical trials [2, 4]. Although statin therapy is successful in reducing CVD events, it has suboptimal success in cohorts enriched with $\mathrm{HeFH}$ [42]. Over a 9-year follow-up period, 39\% of 255 patients studied by Rallidis et al. had a major adverse coronary event despite $84.3 \%$ being on statins, with only $2.3 \%$ achieving LDLC $<70 \mathrm{mg} / \mathrm{dl}$ [42]. Our current study cohort included 25 patients with $\mathrm{HeFH}$ only, 25 with CVD only, 


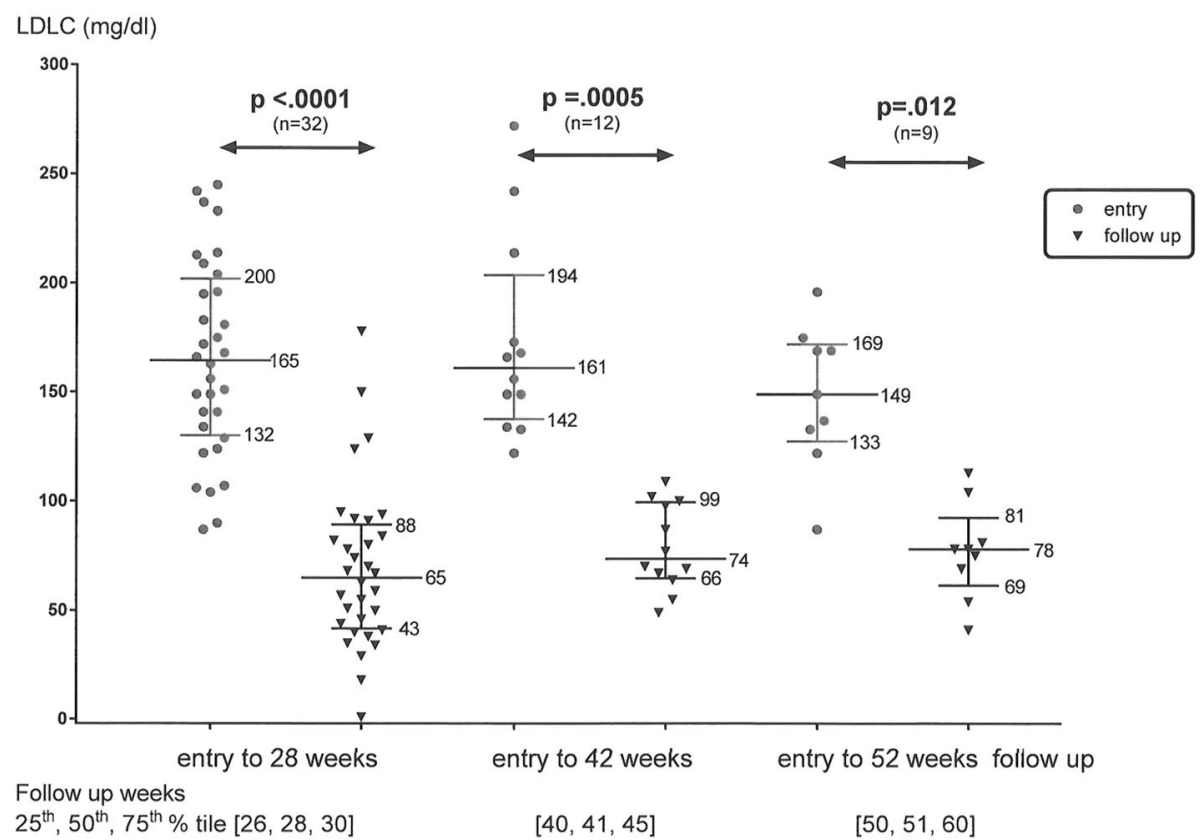

Fig. 2 Change in LDLC from entry to 28, 42, and 52 weeks on Alirocumab $150 \mathrm{mg}(n=18)$ and Evolocumab $140 \mathrm{mg}(n=22)$ every 2 weeks (data pooled); median, 25th and 75th LDLC percentiles displayed

and 19 with both. Moreover, in our current study, on ALI $75 \mathrm{mg}$ Q2W, $52 \%$ of patients had $\geq 1 \mathrm{LDLC}<70 \mathrm{mg} / \mathrm{dl}$, and LDLC was $<70 \mathrm{mg} / \mathrm{dl}$ in $58 \%$ of their measures. On ALI-EVO, $50 \%$ of patients had $\geq 1 \mathrm{LDLC}<70 \mathrm{mg} / \mathrm{dl}$, and $47 \%$ of their LDLC determinations were $<70 \mathrm{mg} / \mathrm{dl}$.

LDLC reduction in current study for ALI-EVO (59\%) was within $2-3 \%$ of that reported in the placebo- controlled trials for ALI $150 \mathrm{mg}(62 \%)^{2}$ or EVO $140 \mathrm{mg}$ $(61 \%)^{4}$ while in the ALI $75 \mathrm{mg}$ group, median LDLC lowering was $39 \%$ compared to $48.9 \%$ in the Odyssey Phase 3 clinical trials [43]. In our cohort where $67 \%$ of patients were statin intolerant, ALI $75 \mathrm{mg}$ and ALI-EVO therapy was successful in high-risk patients with $\mathrm{HeFH}$ and/or CVD who otherwise could not achieve LDLC

Table 3 Number (\%) of patients who had at least one measure of LDLC $<70 \mathrm{mg} / \mathrm{dl}$, and number (\%) of LDLC measurements of LDLC with LDLC $<70 \mathrm{mg} / \mathrm{dl}$ through follow-up on ALI $75 \mathrm{mg}$ every 2 weeks $(n=29)$, or Alirocumab $150 \mathrm{mg}(n=18)$ or Evolocumab $140 \mathrm{mg}(n=22)$ every 2 weeks (ALI-EVO)

\begin{tabular}{|c|c|c|c|c|}
\hline & HeFH only, 25 patients & CVD only, 25 patients & HeFH \& CVD, 19 patients & Total cohort, 69 patients \\
\hline & $\begin{array}{l}\text { Entry LDLC 25th, 50th, } 75 \text { th } \\
\text { percentile }[141,156,181 \mathrm{mg} / \mathrm{dl}]\end{array}$ & $\begin{array}{l}\text { Entry LDLC 25th, 50th, } 75 \text { th } \\
\text { percentile }[90,110,149 \mathrm{mg} / \mathrm{dl}]\end{array}$ & $\begin{array}{l}\text { Entry LDLC 25th, 50th, 75th } \\
\text { percentile }[106,156,204 \mathrm{mg} / \mathrm{dl}]\end{array}$ & $\begin{array}{l}\text { Entry LDLC 25th, 50th, 75th } \\
\text { percentile }[110,143,172 \mathrm{mg} / \mathrm{dl}]\end{array}$ \\
\hline & \multicolumn{4}{|c|}{$\begin{array}{l}\text { number (\%) of patients had LDLC }<70 \mathrm{mg} / \mathrm{dl} \text { at least once during follow up, } \\
\text { number }(\%) \text { of measures with } \mathrm{LDLC}<70 \mathrm{mg} / \mathrm{dl} \text { during follow up }\end{array}$} \\
\hline $\begin{array}{l}\text { ALI } 75 \text { mg/ } \\
2 \text { weeks } \\
\text { Total } 29 \text { patients } \\
65 \text { LDLC } \\
\text { measurements }\end{array}$ & $\begin{array}{l}\text { 2/6 (33\%) patients } \\
8 / 17(47 \%) \text { LDLC } \\
\text { measurements }\end{array}$ & $\begin{array}{l}\text { 11/17 (65\%) patients } \\
\text { 22/35 (63\%) LDLC } \\
\text { measurements }\end{array}$ & $\begin{array}{l}\text { 2/6 (33\%) patients } \\
8 / 13(62 \%) \text { LDLC } \\
\text { measurements }\end{array}$ & $\begin{array}{l}\text { 15/29 (52\%) patients } \\
38 / 65(58 \%) \text { LDLC } \\
\text { measurements }\end{array}$ \\
\hline $\begin{array}{l}\text { ALI-EVO } \\
\text { Total } 40 \text { patients } \\
59 \text { LDLC } \\
\text { measurements }\end{array}$ & $\begin{array}{l}\text { 9/19 (47\%) patients } \\
\text { 12/27 (44\%) LDLC } \\
\text { measurements }\end{array}$ & $\begin{array}{l}6 / 8(75 \%) \text { patients } \\
9 / 12(75 \%) \text { LDLC } \\
\text { measurements }\end{array}$ & $\begin{array}{l}\text { 5/13 (38\%) patients } \\
7 / 20(35 \%) \text { LDLC } \\
\text { measurements }\end{array}$ & $\begin{array}{l}\text { 20/40 (50\%) patients } \\
28 / 59(47 \%) \text { LDLC } \\
\text { measurements }\end{array}$ \\
\hline $\begin{array}{l}\text { All treatment } \\
\text { groups } \\
\text { Total } 69 \text { patients } \\
124 \text { LDLC } \\
\text { measurements }\end{array}$ & $\begin{array}{l}11 / 25 \text { (44\%) patients } \\
20 / 44(45 \%) \text { LDLC } \\
\text { measurements }\end{array}$ & $\begin{array}{l}\text { 17/25 (68\%) patients } \\
31 / 47(66 \%) \text { LDLC } \\
\text { measurements }\end{array}$ & $\begin{array}{l}\text { 7/19 (37\%) patients } \\
15 / 33(45 \%) \text { LDLC } \\
\text { measurements }\end{array}$ & $\begin{array}{l}\text { 35/69 (51\%) patients } \\
66 / 124(53 \%) \text { LDLC } \\
\text { measurements }\end{array}$ \\
\hline
\end{tabular}


Table 4 Change in total cholesterol, triglyceride, HDL cholesterol, and Non-HDL cholesterol in 69 patients treated with Alirocumab 75 mg every 2 weeks $(n=29)$, or Alirocumab $150 \mathrm{mg}(n=18)$ or Evolocumab $140 \mathrm{mg}(n=22)$ every 2 weeks (ALI-EVO)

\begin{tabular}{|c|c|c|c|c|c|c|c|}
\hline \multirow{3}{*}{\multicolumn{2}{|c|}{ Variable measured }} & \multirow{2}{*}{\multicolumn{3}{|c|}{$\begin{array}{l}\text { Alirocumab } 75 \text { mg every } 2 \text { weeks }(n=29) \text { Mean } \pm \text { SD, } \\
\text { median follow-up length } 49 \pm 13,49 \text { weeks } \\
\text { percentile }\end{array}$}} & \multirow{2}{*}{\multicolumn{3}{|c|}{$\begin{array}{l}\text { ALI-EVO }(n=40) \text { Mean } \pm \text { SD, median } \\
37 \pm 12,33 \text { weeks } \\
\text { percentile }\end{array}$}} \\
\hline & & & & & & & \\
\hline & & 25th & 50th & 75th & 25th & 50th & 75th \\
\hline \multirow[t]{6}{*}{ Total cholesterol } & Entry (mg/dl) & 172 & 192 & 230 & 224 & 255 & 288 \\
\hline & Follow up (mg/dl) & 127 & 152 & 173 & 124 & 154 & 180 \\
\hline & Absolute change $(\mathrm{mg} / \mathrm{dl})$ & -14 & -54 & -95 & -71 & -105 & -132 \\
\hline & P (paired Wilcoxon) & $p<.0001$ & & & $p<.0$ & & \\
\hline & Percent change (\%) & -6 & -26 & -38 & -35 & -39 & -49 \\
\hline & P (Wilcoxon) & $p<.0001$ & & & $p<.0$ & & \\
\hline \multirow[t]{6}{*}{ Triglyceride } & Entry (mg/dl) & 96 & 130 & 184 & 129 & 161 & 233 \\
\hline & Follow up (mg/dl) & 81 & 124 & 150 & 90 & 119 & 167 \\
\hline & Absolute change (mg/dl) & +7 & -12 & -53 & -1 & -47 & -102 \\
\hline & P (paired Wilcoxon) & $p=.060$ & & & $p<.0$ & & \\
\hline & Percent change (\%) & +6 & -15 & -29 & -0.3 & -32 & -43 \\
\hline & P (Wilcoxon) & $p=.082$ & & & $p<.0$ & & \\
\hline \multirow[t]{6}{*}{ HDL cholesterol } & Entry (mg/dl) & 40 & 51 & 61 & 42 & 50 & 58 \\
\hline & Follow up (mg/dl) & 41 & 51 & 65 & 49 & 55 & 63 \\
\hline & Absolute change $(\mathrm{mg} / \mathrm{dl})$ & -4 & 0 & +7 & -1 & +5 & +10 \\
\hline & P (paired Wilcoxon) & $p=.40$ & & & $p=.0$ & & \\
\hline & Percent change (\%) & -9 & 0 & +12 & -2 & +8 & +21 \\
\hline & P (Wilcoxon) & $p=.41$ & & & $p=.0$ & & \\
\hline \multirow[t]{6}{*}{ Non-HDL cholesterol } & Entry (mg/dl) & 122 & 136 & 181 & 170 & 201 & 232 \\
\hline & Follow up (mg/dl) & 25 & 50 & 75 & 70 & 92 & 121 \\
\hline & Absolute change $(\mathrm{mg} / \mathrm{dl})$ & -27 & -54 & -94 & -82 & -112 & -131 \\
\hline & P (paired Wilcoxon) & $p<.0001$ & & & $p<.0$ & & \\
\hline & Percent change (\%) & -17 & -37 & -54 & -46 & -54 & -62 \\
\hline & P (Wilcoxon) & $p<.0001$ & & & $p<.0$ & & \\
\hline
\end{tabular}

$<70 \mathrm{mg} / \mathrm{dl}$ with maximal tolerated LDLC lowering regimens.

In our current study, median LDLC was reduced to $68 \mathrm{mg} / \mathrm{dl}$ by ALI 75 and to $70 \mathrm{mg} / \mathrm{dl}$ by ALI-EVO, with $39 \%$ and $59 \%$ reduction from entry on best tolerated LDLC lowering. The median absolute reduction of LDLC on ALI 75 was $43 \mathrm{mg} / \mathrm{dl}$, and on ALI-EVO $91 \mathrm{mg} / \mathrm{dl}$. Reduction of LDLC by $77 \mathrm{mg} / \mathrm{dl}$ for 5 years in 10,000 patients has been estimated to prevent major vascular events in 1000 (10\%), an absolute benefit in those who had pre-existing CVD, and in 500 patients (5\% absolute benefit) in primary prevention [44].

From past vascular studies on statins, regression of plaque can be induced when LDLC is held $\sim 70 \mathrm{mg} / \mathrm{dl}$ or below $[45,46]$. When patients were given rosuvastatin $40 \mathrm{mg}$ in the ASTEROID trial, mean LDLC was reduced from $130 \mathrm{mg} / \mathrm{dl}$ to $60 \mathrm{mg} / \mathrm{dl}$ (53\%), with a total atheroma volume reduction of $6.8 \%$ as well as a significant

Table 5 Comparisons of LDLC change between statin tolerant and intolerant groups

\begin{tabular}{lll}
\hline & Statin tolerant $(n=23)$ & Statin intolerant $(n=46)$ \\
\hline LS means $^{1} \pm$ SE of absolute change in LDLC $(\mathrm{mg} / \mathrm{dl})$ & $-86 \pm 8$ & $-75 \pm 5$ \\
Group differences & $p=.21$ & $-48 \pm 4$ \\
LS means $^{1} \pm$ SE of percentage change in LDLC (\%) & $-58 \pm 7$ & \\
Group differences & $p=.19$ & \\
\hline
\end{tabular}

${ }^{1}$ Least Square means for statin taking and not taking groups, adjusted for PCSK9 treatment (2 groups), treatment duration, age, BMI, race, gender, HeFH (yes-no), CVD (yes-no) and LDLC at entry. 
Table 6 Adverse events in 69 patients. 29 on Alirocumab 75 mg every 2 weeks, and Alirocumab 150 mg $(n=18)$ or Evolocumab $140 \mathrm{mg}(n=22)$ every 2 weeks (ALI-EVO)

\begin{tabular}{|c|c|c|c|}
\hline & $\begin{array}{l}\text { All treatment groups } \\
(n=69)\end{array}$ & $\begin{array}{l}\text { Alirocumab } 75 \text { mg every } 2 \text { weeks } \\
(n=29)\end{array}$ & $\begin{array}{l}\text { ALI-EVO } \\
(n=40)\end{array}$ \\
\hline & $\begin{array}{l}\text { Mean } \pm \text { SD, median } \\
\text { follow-up length }\end{array}$ & $\begin{array}{l}\text { Mean } \pm \text { SD, median } \\
\text { follow-up length }\end{array}$ & $\begin{array}{l}\text { Mean } \pm \text { SD, median } \\
\text { follow-up length }\end{array}$ \\
\hline & $42 \pm 14,40$ weeks & $49 \pm 13,49$ weeks & $37 \pm 12,33$ weeks \\
\hline Flu-like symptoms & $10(14 \%)$ & $1(3 \%)$ & $9(23 \%)$ \\
\hline Respiratory tract infection /symptoms & $2(3 \%)$ & $1(3 \%)$ & $1(3 \%)$ \\
\hline Inject site reaction & $1(1 \%)$ & $1(3 \%)$ & \\
\hline Fatigue & $2(3 \%)$ & $2(7 \%)$ & \\
\hline Headache & $2(3 \%)$ & & $2(5 \%)$ \\
\hline Urticaria /itchiness & $2(3 \%)$ & $1(3 \%)$ & $1(3 \%)$ \\
\hline G.l. symptom & $2(3 \%)$ & & $2(5 \%)$ \\
\hline Weight gain & $2(3 \%)$ & $1(3 \%)$ & $1(3 \%)$ \\
\hline Hair loss & $1(1 \%)$ & & $1(3 \%)$ \\
\hline Any adverse events & $24(35 \%)$ & $7(24 \%)$ & $17(43 \%)$ \\
\hline
\end{tabular}

Compare adverse events (any events) in the 2 treatment groups, $\mathrm{X}^{2}=2.50, p=.11$

reduction in all intravenous ultrasound measurements of atheroma burden [47]. Consequently, in the recent GLAGOV study [20], compared with statin-placebo, the EVO-statin group achieved lower mean LDLC (36.6 vs $93 \mathrm{mg} / \mathrm{dL}, p<.001)$. The primary efficacy parameter, percent atheroma volume (PAV), increased $0.05 \%$ with placebo and decreased $0.95 \%$ with EVO, $p<.001)$. EVO induced plaque regression in more patients than placebo $(64.3 \%$ vs $47.3 \%, p<.001$ for PAV, and $61.5 \%$ vs $48.9 \%$, $p<.001$ for total atheroma volume (TAV). The GLAGOV study also demonstrated a positive linear change in percent PAV as LDLC increased from $20 \mathrm{mg} / \mathrm{dl}$ to $110 \mathrm{mg} / \mathrm{dl}[20]$.
It has been estimated that a lifetime reduction of LDLC $40 \mathrm{mg} / \mathrm{dl}$ would reduce risk of CVD by $50 \%$ [48]. In our current study, the median absolute LDLC reduction ranged from $43 \mathrm{mg} / \mathrm{dl}$ (ALI $75 \mathrm{mg}$ ) to $91 \mathrm{mg} /$ $\mathrm{dl}$ (ALI-EVO), and $53 \%$ of all LDLC measures on therapy were $<70 \mathrm{mg} / \mathrm{dl}$. Moreover, according to the AHA and NIH 10-year CVD risk calculators, on ALI $75 \mathrm{mg}$ there was CVD risk reduction of $20 \%$ and $67 \%$ respectively. On ALI-EVO, by the AHA and NIH calculators, there were $28 \%$ and $78 \%$ reductions estimated in 10 -year CVD risk. The ACC/AHA calculator was not, however, designed for use in patients with pre-existing CVD events, although the NIH calculator has no such

Table 7 Adverse events in 69 patients on Alirocumab 75 mg or Alirocumab 150 mg or Evolocumab $140^{1}$ mg every 2 weeks, by entry statin intolerance group

\begin{tabular}{lll}
\hline & Statin tolerant, taking statin & $\begin{array}{l}\text { Statin intolerant } \\
(n=46)\end{array}$ \\
& $(n=23)$ & Follow up length \\
& Follow up length & 25 th, 50th, 75th \%tile \\
& 25 th, 50th, 75th \%tile & $30,40,52$ weeks \\
\hline Flu-like symptoms & $28,39,16$ weeks & $8(17 \%)$ \\
Respiratory tract infection /symptoms & $2(9 \%)$ & $1(2 \%)$ \\
Inject site reaction & $1(4 \%)$ & $2(4 \%)$ \\
Fatigue & $1(4 \%)$ & $2(4 \%)$ \\
Headache & 0 & $2(4 \%)$ \\
Urticaria /itchiness & 0 & $2(4 \%)$ \\
G.l. symptom & 0 & $1(2 \%)$ \\
Weight gain & 0 & $1(4 \%)$ \\
Hair loss & 0 & $19(41 \%)$ \\
Any adverse events & $5(22 \%)$ & \\
\hline
\end{tabular}

Compare adverse events (any events) in the 2 groups, $\mathrm{X}^{2}=2.59, p=.11$ 
restriction [49]. In at least 50\% of our patients on PCSK9 therapy with LDLC $<70 \mathrm{mg} / \mathrm{dl}$, from the past experience with vascular studies on statins [45-47] and recent GLAGOV [20] study, we speculate that there should be significant regression of vascular plaque.

In the current study, both ALI and EVO were generally well-tolerated; the most significant frequent adverse event was flu-like myositis-myalgia in $14 \%$ of patients overall. There were, however, no differences between groups (ALI 75 vs ALI-EVO) in adverse events $(p=0.11)$. This is comparable to the pattern of side effects for ALI and EVO in randomized placebo-controlled trials [50, 51]. In a meta-analysis of 25 randomized controlled trials with PCSK9 inhibitors, there were no significant differences in major adverse event rates between the active drug and control treatment [52].

A strength of our current report is the extension of post-commercialization follow-up of LDLC lowering and safety in a high risk population from 24 weeks to a mean of 37 weeks for the pooled ALI-EVO group, and to a mean of 49 weeks for patients receiving ALI $75 \mathrm{mg}$ Q2W. A limitation of this study is the relatively small group of patients. A second limitation is a probable bias towards higher risk patients with $\mathrm{HeFH}, \mathrm{CVD}$, and statin intolerance, unable to reach LDLC lowering goals on conventional LDLC-lowering therapy, by virtue of referral to a regional cholesterol treatment center.

\section{Conclusions}

In hypercholesterolemic patients with $\mathrm{HeFH}$, and/or CVD with suboptimal LDLC lowering on maximal tolerated LDLC-lowering therapy at entry, LDLC was reduced 39\% on ALI $75 \mathrm{mg}$ from 115 to a median of $68 \mathrm{mg} / \mathrm{dl}$, and by $59 \%$ on ALI-EVO from 165 to a median of $70 \mathrm{mg} / \mathrm{dl}$. Reported adverse events were minimal and tolerable. ALI and EVO represent paradigm shifts in LDLC lowering.

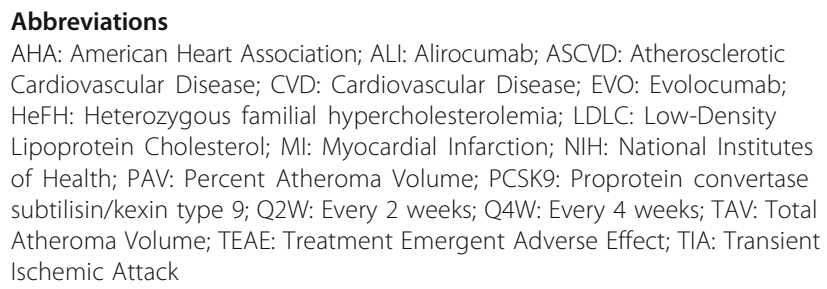
Cardiovascular Disease; CVD: Cardiovascular Disease; EVO: Evolocumab; HeFH: Heterozygous familial hypercholesterolemia; LDLC: Low-Density Lipoprotein Cholesterol; MI: Myocardial Infarction; NIH: National Institutes of Health; PAV: Percent Atheroma Volume; PCSK9: Proprotein convertase subtilisin/kexin type 9; Q2W: Every 2 weeks; Q4W: Every 4 weeks; TAV: Total Atheroma Volume; TEAE: Treatment Emergent Adverse Effect; TIA: Transient Ischemic Attack

\section{Funding}

Lipoprotein Research Fund, Jewish Hospital of Cincinnati.

\section{Availability of data and materials}

Data files available from pxwang@mercy.com.

\section{Authors' contributions}

$J C$ gathered and edited patient data, major contributor in writing the manuscript. AK helped to gather and edit patient data, major contributor in writing the manuscript. MJ gathered and edited patient data. NG, CJ designed the study, edited and analyzed data, major contributors in writing the manuscript. PW provided statistical analysis, major contributor to manuscript. All authors read and approved the final manuscript.

\section{Competing interests}

The authors declare that they have no competing interests.

Consent for publication

Not applicable.

Ethics approval and consent to participate

The study followed a protocol approved by the Jewish Hospital IRB with signed informed consent.

\section{Publisher's Note}

Springer Nature remains neutral with regard to jurisdictional claims in published maps and institutional affiliations.

Received: 6 April 2017 Accepted: 22 May 2017

Published online: 24 July 2017

\section{References}

1. Nissen SE, Stroes E, Dent-Acosta RE, et al. Efficacy and tolerability of Evolocumab vs Ezetimibe in patients with muscle-related Statin intolerance: the GAUSS-3 randomized clinical trial. JAMA. 2016;315(15):1580-90.

2. Robinson JG, Farnier M, Krempf $M$, et al. Efficacy and safety of alirocumab in reducing lipids and cardiovascular events. N Engl J med. 2015;372(16):1489-99.

3. Robinson JG, Kastelein JJ. PCSK9 inhibitors and cardiovascular events. N Engl J med. 2015:373(8):774.

4. Sabatine MS, Giugliano RP, Wiviott SD, et al. Efficacy and safety of evolocumab in reducing lipids and cardiovascular events. N Engl J med. 2015;372(16):1500-9.

5. Sabatine MS, Wasserman SM, Stein EA. PCSK9 inhibitors and cardiovascular events. N Engl J med. 2015;373(8):774-5.

6. Marks D, Thorogood M, Neil HA, et al. A review on the diagnosis, natural history, and treatment of familial hypercholesterolaemia. Atherosclerosis. 2003;168(1):1-14.

7. Austin MA, Hutter CM, Zimmern RL, et al. Genetic causes of monogenic heterozygous familial hypercholesterolemia: a HuGE prevalence review. Am J Epidemiol. 2004;160(5):407-20.

8. Glueck CJ, Shah P, Goldenberg N, et al. Eligibility for PCSK9 treatment in 734 Hypercholesterolemic patients referred to a regional cholesterol treatment center with $\mathrm{LDL}$ cholesterol $>/=70 \mathrm{mg} / \mathrm{dl}$ despite maximal tolerated cholesterol lowering therapy. Lipids Health Dis. 2016;15(1):55.

9. Shah P, Glueck CJ, Jetty $V$, et al. Pharmacoeconomics of PCSK9 inhibitors in 103 hypercholesterolemic patients referred for diagnosis and treatment to a cholesterol treatment center. Lipids Health Dis. 2016;15(1):132.

10. Roth EM. Alirocumab for hyperlipidemia: ODYSSEY phase III clinical trial results and US FDA approval indications. Futur Cardiol. 2016;12(2):115-28.

11. Kereiakes DJ, Robinson JG, Cannon CP, et al. Efficacy and safety of the proprotein convertase subtilisin/kexin type 9 inhibitor alirocumab among high cardiovascular risk patients on maximally tolerated statin therapy: the ODYSSEY COMBO I study. Am Heart J. 2015;169(6):906-15. e913

12. Cannon CP, Cariou B, Blom D, et al. Efficacy and safety of alirocumab in high cardiovascular risk patients with inadequately controlled hypercholesterolaemia on maximally tolerated doses of statins: the ODYSSEY COMBO I| randomized controlled trial. Eur Heart J. 2015;36(19):1186-94.

13. Stroes E, Guyton J R, Lepor N, et al. Efficacy and Safety of Alirocumab 150 mg Every 4 Weeks in Patients With Hypercholesterolemia Not on Statin Therapy: The ODYSSEY CHOICE II Study. J Am Heart Assoc. 2016;5(9): E003421.

14. Colhoun HM, Ginsberg HN, Robinson JG, et al. No effect of PCSK9 inhibitor alirocumab on the incidence of diabetes in a pooled analysis from 10 ODYSSEY phase 3 studies. Eur Heart J. 2016;37(39):2981-9.

15. Robinson JG, Rosenson RS, Farnier M, et al. Safety of very low low-density lipoprotein cholesterol levels with Alirocumab: pooled data from randomized trials. J am Coll Cardiol. 2017;69(5):471-82.

16. Robinson JG, Nedergaard BS, Rogers WJ, et al. Effect of evolocumab or ezetimibe added to moderate- or high-intensity statin therapy on LDL-C lowering in patients with hypercholesterolemia: the LAPLACE-2 randomized clinical trial. Jama. 2014;311(18):1870-82.

17. Koren MJ, Sabatine MS, Giugliano RP, et al. Long-term Low-Density Lipoprotein Cholesterol-Lowering Efficacy, Persistence, and Safety of Evolocumab in Treatment of Hypercholesterolemia. JAMA Cardiol. 2017;2(6): 598-607. 
18. Giugliano RP, Wiviott SD, Blazing MA, et al. Long-term Safety and Efficacy of Achieving Very Low Levels of Low-Density Lipoprotein Cholesterol: A Prespecified Analysis of the IMPROVE-IT Trial. JAMA Cardiol. 2017;2(5):547-555.

19. Sabatine MS, Giugliano RP, Keech AC, et al. Evolocumab and Clinical Outcomes in Patients with Cardiovascular Disease. N Engl J Med. 2017; 376(18):1713-1722.

20. Nicholls SJ, Puri R, Anderson T, et al. Effect of Evolocumab on Progression of Coronary Disease in Statin-Treated Patients: The GLAGOV Randomized Clinical Trial. JAMA. 2016;316(22):2373-2384.

21. Shah P, Glueck CJ, Goldenberg N, et al. Efficacy, safety, low density lipoprotein cholesterol lowering, and calculated 10-year cardiovascular risk reduction of alirocumab and evolocumab in addition to maximal tolerated cholesterol lowering therapy: a post-commercialization study. Lipids Health Dis. 2017;16(1):19.

22. Banach M, Rizzo M, Toth PP, et al. Statin intolerance - an attempt at a unified definition. Position paper from an international lipid expert panel. Expert Opin Drug Saf. 2015;14(6):935-55.

23. Stroes ES, Thompson PD, Corsini A, et al. Statin-associated muscle symptoms: impact on statin therapy-European atherosclerosis society consensus panel statement on assessment, Aetiology and Management. Eur Heart J. 2015;36(17):1012-22.

24. Stone NJ, Robinson JG, Lichtenstein AH, et al. 2013 ACC/AHA guideline on the treatment of blood cholesterol to reduce atherosclerotic cardiovascular risk in adults: a report of the American College of Cardiology/American Heart Association task force on practice guidelines. J am Coll Cardiol. 2014;63(25 Pt B):2889-934.

25. Goff DC, Lloyd-Jones DM, Bennett G, et al. 2013 ACC/AHA guideline on the assessment of cardiovascular risk: a report of the American College of Cardiology/American Heart Association Task Force on Practice Guidelines. Circulation. 2014;129:S49-S73.

26. Hsia SH, Desnoyers ML, Lee ML. Differences in cholesterol management among states in relation to health insurance and race/ethnicity across the United States. J Clin Lipidol. 2013;7(6):675-82.

27. Mann D, Reynolds K, Smith D, et al. Trends in statin use and low-density lipoprotein cholesterol levels among US adults: impact of the 2001 National Cholesterol Education Program guidelines. Ann Pharmacother. 2008;42(9):1208-15.

28. Waters DD, Brotons C, Chiang CW, et al. Lipid treatment assessment project 2: a multinational survey to evaluate the proportion of patients achieving low-density lipoprotein cholesterol goals. Circulation. 2009;120(1):28-34.

29. Jones PH, Nair R, Thakker KM. Prevalence of dyslipidemia and lipid goal attainment in statin-treated subjects from 3 data sources: a retrospective analysis. J am Heart Assoc. 2012;1(6):e001800.

30. Glueck CJ, Budhani SB, Masineni SS, et al. Vitamin D deficiency, myositis-myalgia, and reversible statin intolerance. Curr med res Opin. 2011;27(9):1683-90

31. Khayznikov M, Hemachrandra K, Pandit R, et al. Statin intolerance because of Myalgia, Myositis, Myopathy, or Myonecrosis can in most cases be safely resolved by vitamin D supplementation. N am J med Sci. 2015;7(3):86-93.

32. Knickelbine T, Lui M, Garberich R, et al. Familial hypercholesterolemia in a large ambulatory population: Statin use, optimal treatment, and identification for advanced medical therapies. J Clin Lipidol. 2016;10(5):1182-7.

33. Lakey WC, Greyshock NG, Kelley CE, et al. Statin intolerance in a referral lipid clinic. J Clin Lipidol. 2016;10(4):870-9. e873

34. Sabatine MS, Underberg JA, Koren M, et al. Focus on PCSK9 inhibitors: from genetics to clinical practice. Postgrad med. 2016;128(Suppl 1):31-9.

35. Parker BA, Capizzi JA, Grimaldi AS, et al. Effect of statins on skeletal muscle function. Circulation. 2013;127(1):96-103.

36. Wei MY, Ito MK, Cohen JD, et al. Predictors of statin adherence, switching, and discontinuation in the USAGE survey: understanding the use of statins in America and gaps in patient education. J Clin Lipidol. 2013;7(5):472-83.

37. Everett BM, Smith RJ, Hiatt WR. Reducing LDL with PCSK9 inhibitors-the clinical benefit of lipid drugs. N Engl J med. 2015;373(17):1588-91.

38. Shrank WH, Barlow JF, Brennan TA. New therapies in the treatment of high cholesterol: an argument to return to goal-based lipid guidelines. Jama. 2015;314(14):1443-4.

39. Stein EA, Raal FJ. Lipid-lowering drug therapy for CVD prevention: looking into the future. Curr Cardiol rep. 2015;17(11):104

40. Koren MJ, Scott R, Kim JB, et al. Efficacy, safety, and tolerability of a monoclonal antibody to proprotein convertase subtilisin/kexin type 9 as monotherapy in patients with hypercholesterolaemia (MENDEL): a randomised, double-blind, placebo-controlled, phase 2 study. Lancet. 2012;380(9858):1995-2006.

41. McKenney JM, Koren MJ, Kereiakes DJ, et al. Safety and efficacy of a monoclonal antibody to proprotein convertase subtilisin/kexin type 9 serine protease, SAR236553/REGN727, in patients with primary hypercholesterolemia receiving ongoing stable atorvastatin therapy. J am Coll Cardiol. 2012;59(25):2344-53.

42. Rallidis LS, Triantafyllis AS, Tsirebolos G, et al. Prevalence of heterozygous familial hypercholesterolaemia and its impact on long-term prognosis in patients with very early ST-segment elevation myocardial infarction in the era of statins. Atherosclerosis. 2016;249:17-21.

43. Farnier M, Gaudet D, Valcheva V, et al. Efficacy of alirocumab in high cardiovascular risk populations with or without heterozygous familial hypercholesterolemia: pooled analysis of eight ODYSSEY phase 3 clinical program trials. Int J Cardiol. 2016;223:750-7.

44. Collins R, Reith C, Emberson J, et al. Interpretation of the evidence for the efficacy and safety of statin therapy. Lancet. 2016; 388(10059):2532-2561.

45. Kent SM, Coyle LC, Flaherty PJ, et al. Marked low-density lipoprotein cholesterol reduction below current national cholesterol education program targets provides the greatest reduction in carotid atherosclerosis. Clin Cardiol. 2004;27(1):17-21.

46. Taylor AJ, Kent SM, Flaherty PJ, et al. ARBITER: arterial biology for the investigation of the treatment effects of reducing cholesterol: a randomized trial comparing the effects of atorvastatin and pravastatin on carotid intima medial thickness. Circulation. 2002;106(16):2055-60.

47. Nissen SE, Nicholls SJ, Sipahi I, et al. Effect of very high-intensity statin therapy on regression of coronary atherosclerosis: the ASTEROID trial. Jama. 2006;295(13):1556-65.

48. Ference BA, Yoo W, Alesh I, et al. Effect of long-term exposure to lower low-density lipoprotein cholesterol beginning early in life on the risk of coronary heart disease: a Mendelian randomization analysis. J am Coll Cardiol. 2012;60(25):2631-9.

49. D'Agostino RB Sr, Grundy S, Sullivan LM, et al. Validation of the Framingham coronary heart disease prediction scores: results of a multiple ethnic groups investigation. Jama. 2001;286(2):180-7.

50. US Food and Drug Administration. Highlights of prescribing information: REPATHA ${ }^{\mathrm{TM}}$. 2015. www.accessdata.fda.gov/drugsatfda_docs/label/2015/ 125522s000lbl.pdf. Accessed April 2017.

51. Sanofi/Regeneron. Highlights of prescribing information Praluent. 2015.

52. Zhang XL, Zhu QQ, Zhu L, et al. Safety and efficacy of anti-PCSK9 antibodies: a meta-analysis of 25 randomized, controlled trials. BMC med. 2015:13:123.

\section{Submit your next manuscript to BioMed Central and we will help you at every step:}

- We accept pre-submission inquiries

- Our selector tool helps you to find the most relevant journal

- We provide round the clock customer support

- Convenient online submission

- Thorough peer review

- Inclusion in PubMed and all major indexing services

- Maximum visibility for your research

Submit your manuscript at www.biomedcentral.com/submit
Biomed Central 